\title{
How AI, Data Science and Technology Is Used to Fight the Pandemic COVID-19: Case Study in Saudi Arabia Environment
}

\author{
Esmat Mohamed Abdel Moniem el Sayed ${ }^{1}$ \\ ${ }^{1}$ College of Business, the University of Jeddah, Saudi Arabia \\ Correspondence: Esmat Mohamed Abdel Moniem el sayed, College of Business, University of Jeddah, Saudi Arabia. \\ E-mail: emalsayed@uj.edu.sa
}

Received: July 3, 2020

Accepted: August 19, 2020

Online Published: September 14, 2020

doi:10.5430/rwe.v11n5p409

URL: https://doi.org/10.5430/rwe.v11n5p409

\begin{abstract}
Since the main report of coronavirus (COVID-19) in Wuhan, China, it has spread to almost 100 different nations. As China started its reaction to the infection, it inclined toward its solid innovation division and explicitly man-made brainpower (AI), information science, and innovation to track and battle the pandemic while tech pioneers, including Alibaba, Baidu, Huawei and more quickened their organization's social insurance activities.

This paper focuses on how technology assumed an enormous job in China's endeavors to contain the coronavirus episode and how the Kingdom of Saudi Arabia can use the same methodology and expertise of both China and Germany to avoid the continued spread of the virus. Besides, it clarifies the strong measures taken by The Kingdom of Saudi Arabia to confront political, monetary, social and strict difficulties of COVID-19.
\end{abstract}

Keywords: coronavirus, big data, artificial intelligence, Saudi Arabia, China, U.S., South Korea's, Germany's, Covid-19

\section{Introduction}

While the Chinese government is striving to stop further spread of this lethal infection, Beijing is utilizing huge information assortment and computerized reasoning to check potential contamination causing further spread. Numerous Chinese organizations created applications for individuals to check whether they are going on a similar flight/train in which the confirmed infectious patients are present. According to the state-run Global Time, robots are utilized out in the open spots to reprove voyagers who don't wear covers in the southern Guangdong region. In Beijing, local councils are utilizing flight and train information to keep an eye on the most recent travel reports.

The primary focal point of Chinese specialists is looking for the basic manifestation of this disease "ex: Fever" to be able to prevent further spread. Chinese specialists are utilizing thermometers in neighborhoods and in-office. However, these techniques are impractical for use while voyaging and so, AI and infrared cameras are used for fever detection.

Chinese pursuit monster Baidu built a framework utilizing infrared and facial acknowledgment innovation that sweeps and photographs almost 200 individuals every moment and introduced it in Qinghe station in Bejing. This is quicker than the current warm scanners at air terminals. In case someone's internal temperature is more than or equal 37.3 (99 F), the framework signals caution for an optional check by station staff. Megvii, (Yan Jiang, Amy Wang, 2020) an AI organization built a similar framework used in a tram station in Beijing. To record the spread of coronavirus from Wuhan, Chinese innovation organizations provided automatons conveying clinical supplies (Andersen, K.G., Rambaut, A., Lipkin, W.I. et al, 2020).

In some areas in Beijing, a QR code filter is used by residents to enter individual data (ex: telephone number and address), methods of transportation (ex: tags or flight numbers) and if they visited Hubei territory (of which Wuhan is the capital) in case they contacted someone from this most affected region. (Wrapp, D. et al., 2020).

\section{COVID-19 in the Eastern Mediterranean Region and Saudi Arabia: Avoidance and Helpful Procedures}

On March 22nd, 2020, the World Health Organization (WHO) announced 292142 affirmed cases of COVID-19 with 12748 deaths (WHO, COVID-19 situation report). The infection's focal point later moved from China; where the new case burden declined forcefully, to Europe and the Eastern Mediterranean Region (EMR), where according to the WHO, 19 out of the 22 nations/regions were affected (around 18060 cases and 1010 deaths as of mid-March 2020), mostly located in the Islamic Republic of Iran. 
Despite the difficulties in some EMR nations, including complex crises and overall weaker general wellbeing readiness, the Ministries of Health of 16 of the 22 nations, with the help of WHO and United Nations regional offices, constructed a national activity plan against COVID-19.

Another challenge facing some regions in the EMR (especially Iran, Iraq, and Saudi Arabia) is the occurrence of mass social occasions that impose a challenge for maintaining social distancing measures. In Saudi Arabia, this is seen in the annual Pilgrimage (one of the main pillars of Islam and one of the largest recurring mass gatherings in the world) (Memish ZA, et al., 2020) The number of pilgrims increased from 58,584 in 1920 to 3,161,573 in 2012 (Memish ZA, et al.,2012). Such gathering imposes a huge risk for respiratory disease transmission (Benkouiten $S$ et al., 2019).

The first case of COVID-19 was reported by the Saudi Ministry of Health on March 2nd, 2020 (A citizen returning from Iran), and the 51 contacts of the patient tested negative. The KSA, ahead of many countries, took unprecedented measures to prevent the spread of COVID-19. On February 27th, 2020, for the first time the history of the Muslim pilgrimage, KSA restricted incoming Umrah pilgrimage (Gautret P et al., 2019)

Similar to any communicable disease, early identification is the most important measure for adequate containment. This poses a challenge in the EMR, where the infrastructure to quickly identify and react to COVID-19 cases is lacking. For a newly identified pathogen, this adds additional challenges in the EMR where research centers are not fully developed. This poses difficulties in acquiring the hardware and analytical supplies besides the biosafety and biosecurity challenges.

EMR nations showed reacted variably to the crisis. Many nations implementing a 14-day quarantine to individuals coming from China. A few nations were more forceful than others.

The KSA implemented various measures to limit the spread of COVID-19 including cancellation of the Riyadh International Book Fair and the Saudi Arabian International Horse Festival, suspending the KSA visa program, prohibiting incoming travel from affected regions, and limiting travel between KSA and neighboring Gulf nations. On March 7th, 2020, KSA limited travel to the three significant air terminals inside the Kingdom and required a negative COVID-19 test proof for any incoming individuals. Since the first reported case was in Qatif locale, this territory was placed in lockdown on March 8th, 2020. On March 8th, 2020, the Saudi Ministry of Education announced school and college conclusions. On March 13th, 2020, prohibiting social events was applied. On March 15th, 2020, all international travel was suspended, and all incoming individuals were required to undergo a 14-day quarantine. These strict measures aimed at limiting the spread of the novel COVID-19. The aggregate number of COVID-19 cases in the KSA is presented in Figure 1.

\section{JA. Al-Tawfiq and ZA. Memish/International Journal of Antimicrobial Agents xxx ( $x x x x) x x x$}

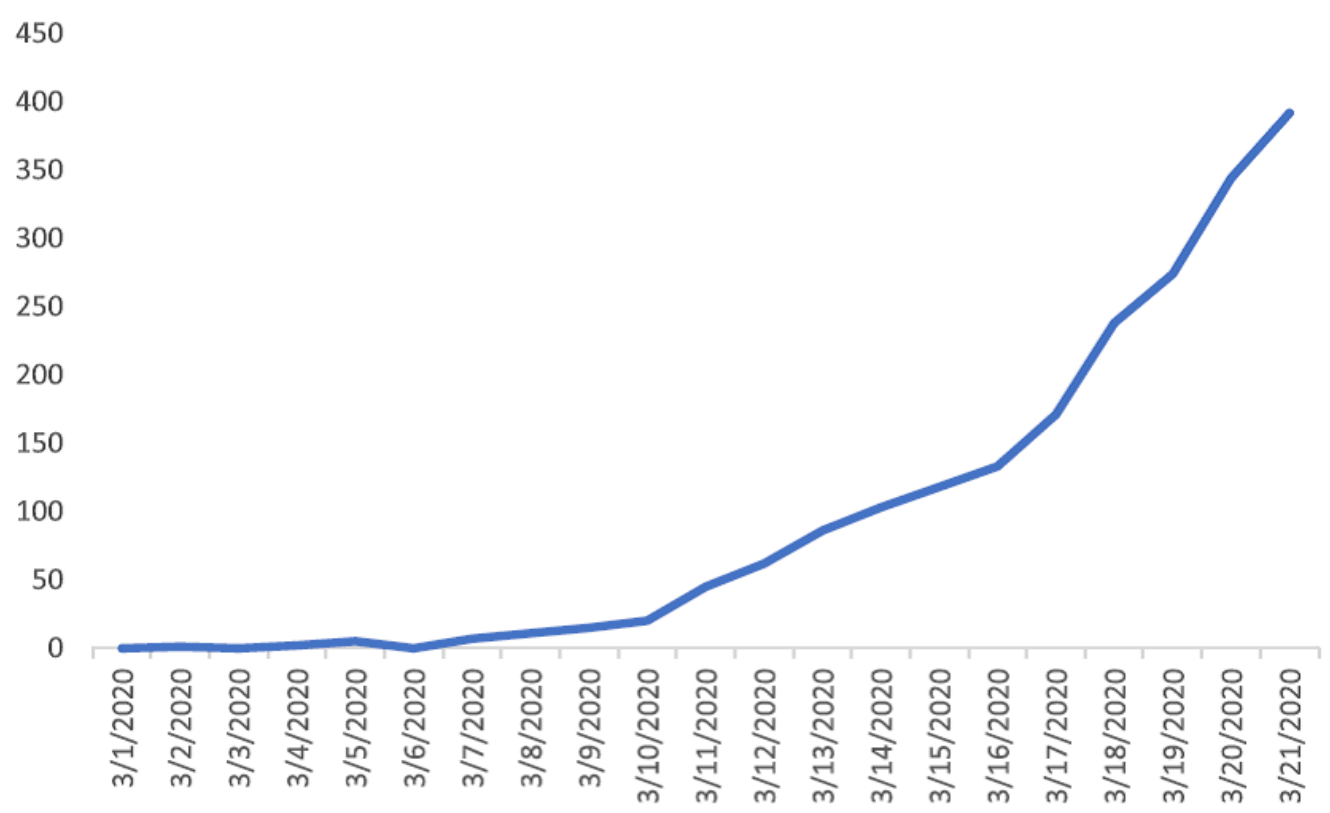

Figure 1. Cumulative daily number of COVID-19 cases in the kingdom of Saudi Arabia 
Regarding the treatment of COVID-19, there is no current standard treatment. Proposed regimens included lopinavir/ritonavir and hydroxychloroquine (Cao B et al., 2020) and (Gautret P et al., 2020). Effectiveness of hydroxychloroquine and azithromycin in decreasing viral burden is reported. In KSA, the current proposed treatment for COVID-19 patients includes hydroxychloroquine administration for all cases. Lopinavir/ritonavir is added to serious cases. This approach is utilized by numerous healthcare settings in the KSA; however, it still needs further clinical testing in randomized clinical trials to establish its effectiveness.

\section{Various Ways Man-Made Consciousness, Information Science, and Innovation Are Being Utilized to Control and Fight COVID-19 (Bernard Marr, 2020)}

\subsection{AI to Recognize and Track the Infection}

Adequately tracking the infection allows for adequate control. AI can predict and identify an occurrence by examining news reports, online networking stages, and government archives. The AI Canadian startup "Blue Dot" cautioned on the risk of infectious episodes a few days before the Centers for Disease Control and the World Health Organization gave their open alerts. (C. Sohrabi et al., 2020)

\subsection{AI to Help Analyze the Infection}

Computerized reasoning organization Infer vision propelled a coronavirus AI arrangement that helps bleeding-edge human services laborers identify and screen the ailment effectively. Imaging offices in social insurance offices are being burdened with the expanded outstanding task at hand made by the infection. This arrangement improves the CT finding speed. Chinese web-based business goliath Alibaba additionally constructed an AI-fueled determination framework they guarantee is $96 \%$ precise at diagnosing the infection right away.

\subsection{AI to Process Human Services Claims}

In addition to the workload burden on the clinical tasks of social insurance frameworks, business and regulatory divisions are burdened as well. Ant Financial offered a block stage chain to help speeding cases handling and reduce the measure of the eye to eye association among patients and medical clinic staff.

\subsection{Drones Convey Clinical Supplies}

To ensure rapid and secure arrival of clinical supplies to their target destination, Land Drone utilized its unmanned ethereal vehicles to ship clinical samples and isolates with limited hazard risk between Xinchang County's sickness control focus and the People's Hospital. Automatons are also used to watch open spaces, track rebelliousness to isolate orders, and for warm imaging.

\subsection{Robots Disinfect, Convey Nourishment and Supplies}

Robots are utilized to the cleaning and sanitization processes as well as transportation of nourishment and medical supplies, hence limiting human-to-human contact. UVD robots from Blue Ocean Robotics use a bright light to eliminate microorganisms. In China, Pudu Technology sent its robots that are commonly used in the food industry to more than 40 emergency clinics around the nation.

\subsection{AI in Drug Development}

Google's Deep Mind division used AI calculations to analyze the infectious proteins and conveyed these discoveries widely to assist in medication development. Benevolent AI uses AI frameworks to synthesize medications and is currently assisting in COVID-19 treatment and is working on proposing the effectiveness of existing medications.

\subsection{AI to Recognize Possible Infected/Exposed People}

China's modern observation framework utilized facial acknowledgment innovation and temperature location programming from Sense Time to identify possibly feverish individuals. The Chinese government also built a checking framework "Health Code" that incorporates enormous information to assess the danger of every individual (ex: assess movement history and time spent in infection hotspots). Residents can get a shading code (red, yellow, or green) through applications like "We Chat" or "Alipay" to identify the need for isolation versus outdoor permission.

\subsection{Chatbots to Share Data}

Individuals can access free online wellbeing conference benefits through applications like "Web Chat". Chatbots are also heavily used to keep individuals aware of the most recent travel regulations.

\subsection{Supercomputers Taking a Shot at a Coronavirus Immunization}

Few tech organizations, for example, Tencent, DiDi, and Huawei offer supercomputers that can very quickly track the improvement of a fix or antibody for the infection, much faster than standard PC. 


\section{Computerized Reasoning and Coronavirus in China: The Latest Chinese Technology to Defeat Coronavirus That Can Be Benefited in Saudi Arabia}

In China, tech movements played a huge role to contain the coronavirus situation. A WHO report summarizing the finding of an authority assessment bunch sent between February 16 and 24, 2020 in China states that the execution of guideline measures was supported by the imaginative and strong usage of forefront developments. Tech types implemented by the Chinese government include.

\subsection{Boost for Chinese Huge Data and AI in Mass Perception}

With the mass movement across stations and air terminals, one of the most perceptible implementations of new developments is using warm scanners to identify the internal heat level of mass individuals at the same time (Daxue Consulting, 2020)

\subsection{Facial Affirmation and Infrared Scanners}

The Chinese AI association, Megvii, declared its facial recognition ability using infrared cameras and observable light. This technology was supported by the Chinese Ministry of Science and Technology and was first passed on a cable car station in Haidan District. This technology can simultaneously check the inner warmth levels of up to 15 people reliably even when using face covers.

Megvii is known to have been boycotted by the US organization in October 2019 for its alleged human rights manhandles. Facial acknowledgment is a debatable subject, even in China. Megvii facial acknowledgment gadgets are being increasingly introduced in the tram, train, and air terminal stations.

\subsection{Shaded QR Codes}

The implementation of enormous data to generate color codes (Alipay's Health code) is another technology technique to control the pandemic (Paul Mozur et al., 2020). Alibaba's part-guaranteed Ant Financial developed a QR code on the standard wallet application "Alipay" available in more than 200 urban networks across China. This code (green, yellow, red) assesses people's risk status. A green code allows free outdoor access, a yellow code requires seven-day separate and a red code requires fourteen-day isolation.

QR code generation relies on data collection about the individual and the region associated with information about coronavirus. A yellow or red code may be hence given to someone who visited or became in contact with individuals from a hotspot zone.

\subsection{Smart CT Scans}

Advancements in coronavirus pneumonia detection by computed tomography (CT) scans are also widely recognized in China. Alibaba and clinical inclusion association Ping'An constructed techniques to provide scans in around 15 seconds with an exactness rate above 90\%. Another Chinese AI startup "Understand Vision" constructed CT scan recognition of pneumonia specifically caused by COVID-19 with speed as fast as 10 seconds. As of March 5th, such a technique has been sent to 34 clinical facilities across China examining more than 32,000 cases.

\section{AI in Covid-19 Control and Potential Implementation by the Kingdom of Saudi Arabia}

China is well known for its advances in the field of computerized reasoning and artificial intelligence. With the COVID-19 pandemic, it utilized AI technologies in constraining mass movements, predicting outbreaks, enhancing genome sequencing and scanner examinations, handle transport robots, and assisting in developing immunization and treatments (A. Chun, 2020).

\subsection{Computerized Reasoning in Reducing Experimentation Time}

The application of AI in structuring the viral protein significantly saved experimentation time. The Chinese development tech, Baidu, in the association with Oregon State University and the University of Rochester, implemented its Linear overlap desire estimation in February 2020 to analyze protein crumbling. This estimation is significantly more concise than standard computations in analyzing viral RNA besides providing information on modes of spread. Such analysis time is reduced from 55 minutes to 27 seconds.

\subsection{Artificial Insight, Onlooker, and Indicator of the Development of the Pandemic}

Early identification and follow up of the pandemic using AI was applied by the Canadian organization "Blue Dot". They utilized AI to audit more than 100 informational collections, (ex: news, carrier ticket deals, socioeconomics, atmosphere information, and creature populaces). They recognized what was at the time, referred to "episode of pneumonia in Wuhan, China” on 31 December 2019 (C. Stieg, 2020). 
A group of specialists at Boston Children's Hospital built an AI called "Health Map" to follow the spread of coronavirus. It utilizes social information, not typically analyzed by disease transmission experts, such as conversation gatherings, for predicting outbreaks and infection follow up (A. Johnson, 2020).

The International Research Center for Artificial Intelligence (IRCAI) in Slovenia, under the sponsorship of UNESCO, implemented "Corona Virus Media Watch", a media framework that reports worldwide and national news and is considered a valuable resource of data for policymakers, the media, and general society to watch rising patterns identified with COVID-19 in their nations and around the globe.

\subsection{Artificial Intelligence to Assist Healthcare Personnel}

In South Korea, AI reduced the time needed to design testing kits based on the genetic make-up of the virus to a few weeks as opposed to the standard two to three months, hence providing mass testing. The biotech company Seegene used its automated test development system to develop the test kit and distribute it widely. This allowed for relative control of the pandemic by having around 18 equipped medical facilities and testing more than 230,000 people (I. Watson et al., 2020).

In Taiwan, a cell phone is given to infected individuals that record their GPS area facilitating police follow up and ensuring staying within their designated areas. Similarly, in Italy, an organization constructed a cell phone application to follow the infected individual's schedule and notify their contacts of possible exposure. This application is allegedly secure ensuring keeping phone numbers and individual information confidential (E. Tebano, 2020). In the United States, achieving the balance between ensuring individual rights and achieving mass segregation is posing a challenge.

Rationalizing the pandemic crisis and prioritizing mass population safety, the U.S. government requested the accessibility of organizations to totaled and unknown information, especially on cell phones, aiming at limiting infection spread (T. Romm et al., 2020). This has to be balanced by lawful hazard and potential picture harm. This brings the discussion of defining the level of crisis in which community safety takes priority over individual rights, however, no basis over the most recent two years on such a law has been established.

During the pandemic, deception levels also increased among informal platforms and the internet including inaccurate news and misinformation about the disease. This issue was addressed by man-made intelligence to fight these wrongful resources. On March 9th, 2020, UNICEF announced its plan to collaborate with the World Health Organization, government specialists, and online platforms including Facebook, Instagram, and LinkedIn to guarantee accurate information supply regarding the infection and correct circulating misinformation. The Council of Europe Committee of Experts announced on March 21st, 2020 that "the emergency circumstance ought not to be utilized as a guide to confine community to data. Nor should States present limitations on media opportunity past the cutoff points permitted by Article 10 of the European Convention on Human Rights" and that "states, together with all media entertainers, ought to endeavor to guarantee a situation helpful for quality news coverage".

\subsection{Assessment of Utilization of Artificial Knowledge in the State of Emergency}

In the unprecedented state of emergency of the current pandemic, data innovation and AI are crucial to help establish an organized approach to dealing with the situation. Article 11 of the European Social Charter provides assurance for wellbeing which authorizes signatories to identify the reasons for sick wellbeing, together with open and private associations, take measures for improvement of such situations and predict the occurrences of plaques or endemics. The advantages of the measures taken during the crisis utilizing AI, including control and mass checking of the population, should be addressed with utmost importance (Y. N. Harari, 2020).

Regarding security assurances in measures utilizing AI to control the crisis (including biometric information access, using facial recognition and geographic localization), principles associated with information safety (example: Convention 108(+) of the European Council) should be completely applied under all conditions and communicated with security specialists ensuring individual information security (A.F. Cahn, John Veiszlemlein, 2020).

\section{Utilizing Sterilization Robots}

With the coronavirus crisis and its high infectivity, utilization of unmanned resources as sterilization robots is extremely crucial especially in clinics with high caseload and emergency settings.

UVD Robots, a Danish organization, is the supply of sterilization robots to China amid the coronavirus situation. These robots have sensors with overlying UV lights for purification, where high doses of UV lights are emitted for a few minutes. These doses are, however, unsafe to human eyes and hence the use of robots (Allison, 2020). 


\subsection{Rapid Delivery of Accurate and up to Date Information}

It is extremely crucial to ensure accurately and most up to date data supply to the population to enhance broad awareness and facilitate preventive measures. However, during the unstable pandemic situation, the rates of inaccurate news and information rise markedly. For these reasons, AI and Big Data in China intensified their technologies to assure accurate information delivery to the Chinese people.

Examples include the measures taken by giant Chinese companies including Baidu, Tencent, Alibaba, and others. They provided a huge data-powered information center on their platforms aiming at delivering the latest and most accurate news about COVID-19, displaying statistics, infection rates, nearest hospitals, and testing centers as well as online clinical consultation. This last feature was utilized by around $34 \%$ of the Chinese people.

\subsection{AI in Mapping}

In China, Baidu constructed an AI-based map to help individual awareness and avoidance of possible dangerous routes. These maps include: 'pestilence map' which shows the number of suspected cases in a region, 'relocation pattern map' helps individuals check the movement status of Mainland urban areas, and 'resumption work map' showing all open stores in a region.

\subsection{Big Data Platforms to Help the Chinese Government With Decision Making}

The modes by which AI enormously helped guide decision making are vastly wide. In China, more than 20 province's government worked with tech companies to construct AI to report COVID-19 related data and feedback.

Two months after the outbreak, authorities are trying to find a balanced approach to resume economic and social development recovery and control the infection. And since AI is very important in different aspects of the pandemic, the Chinese government announced its focus on enhancing the new infrastructures including 5G networks and data centers.

\section{Germany's Low COVID-19 Death Rates}

Germany's death rates have been found to be the least among the 10 nations severely affected by the pandemic: $0.3 \%$ in contrast to $9 \%$ in Italy and $4.6 \%$ in the UK.

This difference was particularly interesting since Italy and Germany both have many the population above the age of 65. However, Lothar Wieler, the leader of the Robert Koch Institute (RKI), the administration's focal general wellbeing body expected that over the long course of time, no huge difference would be expected between the death rates among the 2 populations.

\section{South Korean Methodology}

South Korea has announced the least number of new cases since the start of the pandemic. One of its methodologies is the widescale testing of almost 20,000 individuals daily, making this the largest number of tested individuals per capita in the world. It utilized large numbers of open and private labs as well as many drive-thru testing's centers for individuals to check their wellbeing status.

South Korea utilized its experience in dealing with the outbreak of Middle East Respiratory Syndrome (MERS) in 2015 when 36 people were infected, making this the highest number of confirmed cases after Saudi Arabia.

Because of this MERS outbreak, South Korea's Centers for Disease Control built a separate division for dealing with such similar crises. This measure has definitely proven to be valuable in the COVID-19 pandemic. Besides that, laws related to individual data access in cases of emergency situations also changed after MERS, where legislature cautioned individuals if they were in a region where confirmed cases are found, using phone notifications. The legislature also requested strict measures in the masses by temperature check and maintain a 2-meter social distance in gatherings.

South Korea as such set an example to the world in controlling the pandemic while limiting economic loss. On March 18th, 2020, the number of new COVID-19 cases decreased to less than 100 cases for the 4th day from 909 new cases on February 29th, 2020.

\section{Successful Implementation of Robots in Fighting COVID-19 Pandemic}

Coronavirus pandemic created innovative ideas in various fields, using robots is an example of these areas. In Europe, robots were successfully utilized in helping fight the pandemic, hence limiting human exposure and adding an additional safety measure to personnel. (EU Robotics, 2020). Presented here areas where robots were and are still implemented during the COVID-19 pandemic. 


\subsection{Robots Navigating Hospitals and Clinics}

In designated clinics and wards for COVID-19 patients, robots were very useful in limiting human interactions. Bucharest Robots incorporated a UVD robot that sanitized space of 7500 sqm in only a couple of hours, two robots that offered data to patients, and one server robot that conveyed food, all with no human contact.

\subsection{Robots Sanitizing Wards Independently}

UVD, the Danish cleansing robot, can independently purify contaminated areas without assistance from the clinical staff. It uses UV-C lights for sterilization. The UVD sanitization robot created by Blue Ocean Robotics, together with UVD Robots and Odense University Hospital, won the EU Robotics Technology Transfer Award of 2020.

\subsection{Robots Independently Coordinating and Conveying Medications, Blood Tests, and Food}

In Barcelona, Catalunya, Spain, the TIAG Base robot of PAL Robotics can independently convey food as well as prescriptions and tests in a busy setting as an emergency room.

\subsection{Robots Protecting Specialists From COVID-19 Infection}

In Italy, Tommy, robot nurture was used in emergency clinics in Varese, Lombardi. It enters patients' rooms and monitor clinical parameters from equipment in the room then relay such information to the clinical team. It also has a touch screen face allowing patients to send messages to the healthcare staff. This is extremely useful in limiting contact time and hence potential exposure of the health care personnel to coronavirus.

In Valencia, Spain, Robotnik created a portable robot that acts as an interface providing patient status remotely.

In Denmark, Life Science Robotics (LSR) created ROBERT, a robot helping physiotherapists inpatient mobilization and rehabilitation. This has proven beneficial during the COVID-19 situation minimizing human contact.

\subsection{Robots Accelerating COVID-19 Testing}

Since testing as many individuals as possible in the shortest time possible is crucial during the pandemic to limit the infection rates, different countries are utilizing robots to achieve such a task while maintaining human safety and limiting contact. In March, Spain announced using automated testing utilizing robots that will be able to run around 80,000 tests every day. In Belgium, The Liege Hospital Center, in collaboration with the Swiss organization Roche, got the "COBAS 6800" robot to support their testing capacity.

\subsection{Robots Maintaining Necessary Social Interaction During COVID-19 Pandemic}

Due to the social restrictions imposed by COVID-19, social connections while maintaining social distancing become challenging. In Belgium, Zorabots made all its James robots available to retirement homes, free of charge, to ensure that patients and their families and friends remain in touch without risking human contact. These robots, unlike smartphones, are mobile and can move from room to room, ensuring essential emotional support and necessary social interaction.

\subsection{Robots in Population Education}

Pepper robots are used in Germany to remind shoppers to maintain social distancing.

\section{Vital Measures Implemented by the Kingdom of Saudi Arabia to Fight COVID-19}

Nations that implemented early active and preventive measures achieved fewer infection rates and flattened their spread curves. (Fisher D et al., 2020). Countries that had experience with somehow similar episodes (ex: Singapore during the Severe Acute Respiratory Syndrome outbreak) provided an ideal model (Lee V.J et al., 2020).

In Saudi Arabia, several challenges are imposed in dealing with the COVID-19 pandemic, especially in applying strict social measures. Such challenges are manifested in the nature of the community with the degree of urbanization and the strict social standards in addition to the application of yearly strict mass get-togethers in accordance with KSA 2030 vision for financial and social progression (Kingdom of Saudi Arabia vision 2030, 2016).

Another challenge in Saudi Arabia is the religious nature of the country. It is a major holy place in Islam where Makkah and Medina are home to the two Holy mosques. Every year, KSA hosts more than 10 million visitors from over 180 nations for the Hajj and Umrah. The Hajj, which is one of the main pillars of Islam, is an annual event occurring on the 12th month of the Islamic calendar and Umrah is a year-long worshipping occasion (Yezli S et al., 2017). These occasions impose huge mass gatherings increasing the possibilities of respiratory illness transmission. (Kok J et al., 2012). Besides, transmission intensification and rapid worldwide spread can occur through a huge number of returning visitors (Kok J et al., 2012). In addition to these occasions, Mosques hold the 5-time daily supplications and the Friday noon prayer, the latter is attended by a greater number of worshippers every week. (Yezli S et al., 2016). 
Specialists in KSA were very alert since the start of the pandemic and were vigilantly following the situation evolution with plans executed to be placed into action. Such plans included measures for the early limiting of social gatherings. On the 27th of February 2020, the KSA suspended the Umrah program, an unprecedented movement for some decades. Despite the social, financial, and political consequences associated with this decision, it was viewed as a necessary legitimate measure for the general wellbeing (Ebrahim S.H., Memish Z.A., 2020).

On March 2nd, 2020, the principal case of COVID-19 was declared by Saudi specialists. The case was a Saudi national who returned from Iran. On March 7th, the Saudi Ministry of Sports placed all game rivalries on hold as well as the Saudi Olympics Games which were scheduled on March 23rd, 2020. On March 8th, 2020, the Saudi Ministry of Education announced school conclusion and suspended face to face interactions at colleges and other educational institutions including open, private, and specialized training facilities, until further notice. Until March 9th, cases were reported only in individuals coming from overseas with total cases of 20 and 5 new cases. However, on March 10th, neighborhood transmission was reported. This resulted in the application of more strict measures to limit social interactions that allow close contact and hence, increase the risk of transmission among individuals. Such measures included a wider range of suspension of festivities, social gatherings including weddings and burial services, and meetings as well as temporary closure shopping centers and restaurants. This was replaced by telecommunication, video chatting, restaurant takeaways, and online shopping. Sports were also suspended on March 14th until further notice. Stores that supply basic individual needs, like grocery stores, remained open with prolonged working hours so as to ensure adequate social distancing.

As the situation evolved worldwide with increasing case numbers, the government, together with the Saudi Council of Senior Scholars, decided on the temporary closure of the Kingdom's 80,000 mosques and suspension of the Friday prayer. Besides that, the two Holy mosques of Makkah and Medina were also temporarily closed to limit spread and ensure population wellbeing. Those measures were very essential and very strong in the essence that religion plays an incredibly significant role in the KSA and the Muslim world. These measures were rationalized and balanced with the severity of the situation and the priority of the general population's wellbeing.

With more increase in case numbers, the Kingdom announced on March 20th, 2020, the suspension of transportation subject to mass gatherings including air traffic, taxicabs, and public transports. Of particular safety concerns are taxicabs, that are utilized by a large number of individuals daily, creating a hazard for both the drivers and the clients. However, for the urgent requirements of taxicabs by certain individuals, taxi sharing applications were still accessible with limited capacity.

Despite the abovementioned measures, social gatherings were partly taking place, especially at night. This prompted the Saudi Authorities to announce partial curfew starting March 23rd, 2020 from $7 \mathrm{pm}$ to 6 am where individuals were required to stay at home with exceptions in individuals with approvals or for extraordinary situations. Later, in certain urban communities including Riyadh, Makkah, and Medina, these hours were extended to be from $3 \mathrm{pm}$ till 6 am. Breaking such rules was associated with legal punishments, including paying a fine and other lawful consequence. During the SARS outbreak, such an application of punishments for violating these rules ensured individual compliance in multiple nations. (Wilder-Smith A., Chiew C.J., Lee V.J., 2020).

On March 26th, 2020, three COVID-19 related fatalities were recorded by the Kingdom. Even though this number was significantly less than other nations, strict measures remained in place and were proven effective in the long term to flatten COVID-19 related curves.

Such measures, being a part of the Hazard correspondence approach of the Kingdom, have proven vital in damage limitation and infection control. Saudi specialists and authorities are constantly on the watch for the COVID-19 situation evolution. On March 26th, the Kingdom implemented a crisis culmination on COVID-19 by utilizing its present administration of G20.

While these restricting measures are rationalized and practical in the short term, they may not be practical in the long term in case the situation persists. However, if these measures are eased, infection relapses and more serious transmissions may occur (Ferguson N M., Laydon D., Nedjati-Gilani G. 2020). These call for innovative alternative strategies that are more practical (Fisher D., Wilder-Smith A., 2020) (Wilder-Smith A., Chiew C.J., Lee V.J., 2020) Examples include irregular social removing guided by the study of illness pattern information, with the resumption of social distancing strictly if the number of cases rises (Ferguson N M., Laydon D., Nedjati-Gilani G. 2020). In the case of COVID-19 progression, more proactive measures may be needed. These include active surveillance of infected cases and their isolation, via tracing their contacts and travel limitations or restrictions. (Fisher D., Wilder-Smith A., 2020). 


\section{Summary and Conclusion}

In their battle against MERS, South Korea analyzed the errors that cost them valuable time in their management of the situation. These included ignoring the data regarding MERS dangers presented by the World Health Organization. Even though no MERS cases were recorded in Bahrain at the time, it was still regarded as a hazard zone by the WHO due to previous episodes of MERS outbreaks. South Korea however, unlike other countries like the United States, didn't add Bahrain to its list of hazardous zones, and hence individuals with flu-like symptoms from Bahrain were overlooked as may have had MERS and were not therefore tested. In addition to that, rates of MERS transmission were significantly very high in healthcare emergency settings where 85 of the 186 confirmed MERS cases were reported among healthcare workers at the Samsung Medical Center. Analysis of the situation at the time showed that healthcare settings were not ready to handle such communicable diseases due to several reasons, including the limited number of negative pressure isolation rooms.

Because of lessons learned during the MERS situation, South Korea implemented a chain response in the community to halt transmission which was evident during the COVID-19 pandemic. However, an uncooperative individual can disturb such a chain and lead to disease flares. This highlights the utmost importance of dynamic interest and social cooperation by all the population.

In South Korea, religion is a vital component of culture. This brings the discussion of whether the government can limit social religious events owing to the pandemic in balance with the insurance of opportunity of religion in the Korean constitution. On March 13th, another coronavirus case was detected in Sonogram, a city near Seoul. This case was associated with the River of Grace Community Church.

One of the vital measures during such pandemic is population education and providing accurate and up to date information to the people to ensure adherence to social restriction rules. The Canadian organization Blue Dot implemented AI in early identification of the infection, when it was still described as "episode of pneumonia in Wuhan, China" and gathered as much data as possible from various sources including news, carrier ticket deals, socioeconomic, and atmosphere information. These wide data collections need to be balanced with ensuring that no falsified information be provided, especially in the chaotic situation of the pandemic. To guarantee accurate information, the Big Data in China focused its effort on educating the population and ensuring legitimate data reliance.

Finally, despite The Kingdom of Saudi Arabia placing strict measures in facing this pandemic, it is still expected to go up against political, monetary, and social concerns to ensure the general safety of the population, especially with the Kingdom playing a vital role in the whole Islamic world.

\section{References}

Abdul Salam, A., Elsegaey, I., Khraif, R., \& Al-Mutairi A. (2014). Population distribution and household conditions in Saudi Arabia: reflections from the 2010 Census. SpringerPlus, 3, 530.

Ahmed, Q. A., \& Memish, Z. A. (2020). The cancellation of mass gatherings (MGs)? Decision making in the time of COVID-19. Trav Med Infect Dis., 101631.

Allison, D. (2020). UVD robots to push AI innovation in China during the Coronavirus epidemic. Retrieved 19 March 2020, from https://daxueconsulting.com/ai-and-the-coronavirus-in-china/

Al-Tawfiq, J. A., Zumla, A., \& Memish, Z. A. (2014). Coronaviruses: severe acute respiratory syndrome coronavirus and Middle East respiratory syndrome coronavirus in travelers. Corroding Infect Dis, 27, 411-17.

Andersen, K. G., Rambaut, A., Lipkin, W. I. et al.. (2020). The proximal origin of SARS-CoV-2. Nat Med. https://doi.org/10.1038/s41591-020-0820-9

Baidu. (2020). How Baidu is carrying AI to the battle against coronavirus. MIT Technology Review, 11 March 2020.

Benkouiten, S., Al-Tawfiq, J. A., Memish, Z. A., Albarrak, A., \& Gautret, P. (2019). Clinical respiratory infections and pneumonia during the Hajj pilgrimage: a systematic review. Travel Med Infect Dis, 28, 15-26. https://doi.org/10.1016/j.tmaid.2018.12.002

Bernard, M. (2020). Strategic business \& technology advisor to governments and companies, use data more intelligently, artificial intelligence, big data, block chains, and the Internet of Things. Retrieved from https://www.forbes.com/sites/bernardmarr/2020/03/13/coronavirus-how-artificial-intelligence-data-science-andtechnology-is-used-to-fight-the-pandemic/\#454650045f5f

Bin Nafisah, S., Alamery, A. H., Al Nafesa, A., Aleid, B., \& Brazanji, N. A. (2018). School closure during novel influenza: a systematic review. J Infect Public Health, 11(5), 657-661.

Boyle. (2020). White House looks for the guide of tech titans to battle coronavirus and deception. GeekWire, March 11, 2020. 
Cahn, A. F., \& Veiszlemlein, J. (2020). COVID-19 tracking data, and surveillance risks are more dangerous than their rewards. NBC News, 19 March 2020.

Cao, B., Wang, Y., Wen, D., Liu, W., Wang, J., Fan, G., et al.. (2020). A trial of lopinavirritonavir in adults hospitalized with severe Covid-19. N Engl J Med. https://doi.org/10.1056/NEJMoa2001282

Chun. (2020). In a period of coronavirus, China's interest in AI is paying off in a major way. South China Morning Post, 18 March 2020.

Ebrahim, S. H., \& Memish, Z. A. (2020). COVID-19 - the role of mass gatherings. Trav Med Infect Dis., 101617.

Ebrahim, S. H., \& Memish, Z. A. (2020). Saudi Arabia's measures to curb the COVID-19 outbreak: temporary suspension of the Umrah pilgrimage. J Trav Med. https://doi.org/10.1093/jtm/taaa029

Ebrahim, S. H., Ahmed, Q. A., Gozzer, E., Schlagenhauf, P., \& Memish, Z. A. (2020). Covid-19 and community mitigation strategies in a pandemic. BMJ, $368, \mathrm{~m} 1066$.

EuRobotics. Scuola di Robotica, in Italian, report, Aljazeera, IEEE report from China. Retrieved 30 April, 2020, from https://www.eu-robotics.net/eurobotics/newsroom/press/robots-against-covid-19.html

Fake news" and disinformation about the SARS-CoV2 coronavirus. INSERM, 19 February 2020.

Ferguson, N. M., Laydon, D., \& Nedjati-Gilani, G. (2020). Impact of non-pharmaceutical interventions (NPIs) to reduce COVID19 mortality and healthcare demand.

Fisher, D., \& Wilder-Smith, A. (2020). The global community needs to swiftly ramp up the response to contain COVID-19. Lancet, 395(10230), 1109-1110.

Gautret, P., Al-Tawfiq, J. A., \& Hoang, V. T. (2020). Covid 19: will the 2020 Hajj pilgrimage and tokyo olympic games be cancelled?. Trav Med Infect Dis., 101622.

Gautret, P., Lagier, J-C., Parola, P., Hoang, V. T., Meddeb, L., Mailhe, M., et al.. (2020). Hydroxychloroquine and azithromycin as a treatment of COVID-19: results of an open-label non-randomized clinical trial. Int J Antimicrob Agents, 105949. https://doi.org/10.1016/j.ijantimicag.2020.105949

Harari, Y. N. (2020). Yuval Noah Harari: the world after coronavirus. The Financial Times, 20 March 2020.

Jaffar, A. A-T., Ziad, A., \& Memish, D. (2020). Specialty Internal Medicine and Quality Department, Johns Hopkins Aramco Healthcare, Dhahran, Saudi Arabia, Indiana University School of Medicine, Indianapolis, IN, USA, Johns Hopkins University School of Medicine, Baltimore, MD, USA, King Saud Medical City, Research Center, Ministry of Health, Saudi Arabia, Al-Faisal University, Riyadh, Saudi Arabia, Hubert.

Jumper, J., Tunyasuvunakool, K., Kohli, P., Hassabis, D., et al.. (2020). Computational expectations of protein structures related with COVID-19. Deep Mind, 5 March 2020.

Kingdom of Saudi Arabia vision 2030. (2016). Retrieved from http://vision2030.gov.sa/download/file/fid/417

Knight, W. (2020). Researchers Will Deploy AI to Better Understand Coronavirus. Wired, March 17, 2020.

Kok, J., Blyth, C. C., \& Dwyer, D. E. Mass gatherings and the implications for the spread of infectious diseases. Future Microbiol, 7(5), 551-553.

Lardinois, F. (2020). IBM, Amazon, Google and Microsoft band together with White House to give figure assets to COVID-19 research. TechCrunch, 22 March 2020.

Lee, V. J., Chiew, C. J., \& Khong, W. X. Interrupting transmission of COVID-19: lessons from containment efforts in Singapore. J Trav Med. https://doi.org/10.1093/jtm/taaa039

Li, C. (2020). How DAMO Academy's AI System Detects Coronavirus Cases. Alizila, March 10, 2020.

Litvinova, M., Liu, Q. H., Kulikov, E. S., \& Ajelli, M. (2019). Reactive school closure weakens the network of social interactions and reduces the spread of influenza. Proc Natl Acad Sci U S A., 116(27), 13174-13181.

Memish, Z. A., Al-Tawfiq, J. A., Almasri, M., Azhar, E. I., Yasir, M., Al-Saeed, M. S., et al.. (2017). Neisseria meningitides nasopharyngeal carriage during the Hajj: a cohort study evaluating the need for ciprofloxacin prophylaxis. Vaccine, 35, 2473-8. https://doi.org/10.1016/j.vaccine.2017.03.027

Memish, Z. A., Zumla, A. A. L., Hakeem, R. F., Assiri, A., Turkestani, A., Al Harby, K. D., et al.. (2014). Hajj: infectious disease surveillance and control. Lancet, 383, 2073-82.

Mozur, P., Zhong, R., \& Krolik, A. (2020). In Coronavirus Fight, China Gives Citizens a Color Code, With Red Flags. $\begin{array}{lllll}\text { Retrieved } & 1 & \text { March } & 2020, & \text { from }\end{array}$ https://www.nytimes.com/2020/03/01/business/china-coronavirus-surveillance.html 
Murdock, J. (2020). Staff reporter for Newsweek. Retrieved from https://www.newsweek.com/china-technology-covid-19-coronavirus-apps-alipay-health-code-u-s-outbreak-spre ad-1490941

National Health Commission of the PRC. Retrieved April 19, 2020, from http://en.nhc.gov.cn/2020-04/19/c79363.html

Pennisi, M. (2020). Coronavirus, come funzionano il controllo delle celle e il tracciamento dei contagi. Il Garante: «Non bisogna improvvisare», Corriere della Sera, 20 March 2020.

Ratnam, G. (2020). Can AI Fill in the Blanks About Coronavirus? Think So Experts. Government Technology, 17 March 2020.

Romm, T., Dwoskin, E., \& Timberg, C. (2020). U.S. government, tech industry talking about approaches to utilize cell phone area information to battle coronavirus. The Washington Post, March 18, 2020.

Scola, N. (2020). Big Tech faces an 'Older sibling' trap on coronavirus. POLITICO, 18 March 2020.

Simonite, T. (2020). Chinese Hospitals Deploy AI to Help Diagnose COVID-19. Wired, February 26, 2020.

Sohrabi, C., Alsafi, Z., O'Neill, N., Khan, M., Kerwan, A., Al-Jabir, A., et. al.. (2020). World Health Organization declares global emergency: are view of the 2019 novel coronavirus (COVID-19). Int. J. Surg. 76, 71-76.

Stieg, C. (2020). How this Canadian start-up spotted coronavirus before everyone else knew about it. CNBC, March 3, 2020.

Tebano, E. (2020). Coronavirus, pronta la application italiana per tracciare I contagi: 'Così possiamo fermare l'epidemia'. Corriere della Sera, 18 March 2020.

Watson, S., Jeong, J., \& Hollingsworth, T. (2020). Booth, how this South Korean company created coronavirus test kits in three weeks. CNN World, March 13, 2020.

Wilder-Smith, A., Chiew, C. J., \& Lee, V. J. (2020). Can we contain the COVID-19 outbreak with the same measures as for SARS?. Lancet Infect Dis. https://doi.org/10.1016/S1473-3099(20)30129-8

World Health Organization. (2020). Coronavirus disease 2019 (COVID-19) situation report - 65. Geneva, Switzerland, 2020.

Wrapp, D., et al.. (2020). RAPP Cryo-EM structure of the 2019-nCoV spike in the prefusion conformation. Science, 1260-1263.

Xie, Y., \& Yang, X. Brunswick Group, Megvii Technology Limited. Retrieved from https://megvii.com/en/news/

Yakobovitch, D. (2020). How to battle the Coronavirus with AI and Data Science. Medium, 15 February 2020.

Yan, J., \& Wang, A. (2020). Megvii: New software equipped with facial recognition and temperature checking cameras], Using AI to combat the novel coronavirus outbreak. Retrieved from https://megvii.com/en/news/ID?news_,id=111

Yezli, S., \& Khan, A. A. (2020). The Jeddah tool. A health risk assessment framework for mass gatherings. Saudi Med J., 4l(2), 121-122.

Yezli, S., Assiri, A. M., Alhakeem, R. F., Turkistani, A. M., \& Alotaibi, B. (2016). Meningococcal disease during the Hajj and Umrah mass gatherings. Int J Infect Dis., 47, 60-64.

Yezli, S., Yassin, Y., Awam, A., Attar, A., Al-Jahdali, E., \& Alotaibi, B. U. (2017). An opportunity for mass gatherings health research. Saudi Med J., 38(8), 868-871.

Zhou, P., Yang, X. L., Wang, X. G., Hu, B., Zhang, L., Zhang, W., et al.. (2020). A pneumonia outbreak associated with a new coronavirus of probable bat origin. Nature. https://doi.org/10.1038/s41586-020-2012-7

\section{Copyrights}

Copyright for this article is retained by the author(s), with first publication rights granted to the journal.

This is an open-access article distributed under the terms and conditions of the Creative Commons Attribution license (http://creativecommons.org/licenses/by/4.0/). 